\title{
Advanced Interchangeable Dynamic Simulation Model for the Optimal Design of a Fuel Cell Power Conditioning System
}

\author{
Jong-Soo Kim*, Gyu-Yeong Choe*, Byoung-Kuk Lee ${ }^{\dagger}$ and Jae-Sun Shim**
}

\begin{abstract}
This paper presents an advanced dynamic simulation model of a proton exchange membrane fuel cell for the optimal design of a fuel cell power conditioning system (FC-PCS). For the development of fuel cell models, the dynamic characteristics of the fuel cell are considered, including its static characteristics. Then, software fuel cell simulation is realized using Matlab-Simulink. Specifically, the design consideration of PCS (i.e., power semiconductor switch, capacitor, and inductor) is discussed by comparatively analyzing the developed simulator and ideal DC source. In addition, a cosimulation between the fuel cell model and PCS realized using the PSIM software is performed with the help of the SimCoupler module. Detailed analysis and informative simulation results are provided for the optimal design of fuel cell PCS.
\end{abstract}

Keywords: Dynamic simulation, Fuel cell, Power conditioning system, Modeling and simulation, Optimal design

\section{Introduction}

The growing concerns about environmental pollution and energy shortages have made renewable technologies an attractive option. Fuel cell technology can play an active role in meeting the growing demands for renewable energy. Therefore, a fuel cell power conditioning system (FC-PCS) that convert unregulated DC source to regulated AC is necessary. Designers should understand the characteristic of the source for the optimal design of PCS because a fuel cell has inherent nonlinear and dynamic characteristics resulting from electrochemical reactions (Fig. 1); that is, the difference between the output characteristic of the fuel cell and the DC source should be considered in PCS designs. Without this consideration, development of PCS with high performance and efficiency is impossible [1]-[3].

Until now, the modeling of the fuel cell stacks is performed through various methods in order to understand fuel cell characteristics. The electrical impedance model for fuel cells using passive components like resistors, inductors, and capacitors is explored [4], [5]. In advanced methods, the electrical circuit model using bipolar junction transistors, diodes, inductors, and capacitors based on Pspice is performed [6]. Using computational fluid dynamics (CFD) with highly complicated electrochemical and mechanical equations, the internal and external characteristics of the fuel cell stack are modeled in different ways [7]. Some studies derived a steady-state equation for the dynamic behavior of the fuel cell using complicated electro-

$\dagger \quad$ Corresponding Author: School of Information and Communication Engineering, Sungkyunkwan University, Korea. (bkleeskku@skku.edu)

* School of Information and Communication Engineering, Sungkyunkwan University, Korea.

** Department of Electrical Engineering, Kangwon National University at Samcheok, Korea.

Received: March 22, 2010; Accepted: July 21, 2010 chemical equations [8], [9]. Even though these models sufficiently reflected the characteristics of the fuel cell itself, analyzing the PCS for fuel cell power generation system based on these models is difficult because fuel cell and the PCS are analyzed separately [9], [10].

This paper presents an advanced dynamic simulation model of a proton exchange membrane fuel cell (PEMFC) that can be used interchangeably in the simulation of the PEMFC and PCS for optimal FC-PCS design. For this purpose, the authors structurally summarized the complicated electrochemical equations from the viewpoint of power electronics point of view and its application in PCS design. The nonlinear characteristics of the PEMFC are mathematically modeled and the transient voltage dynamics is explored. The feasible dynamic simulation model is then implemented using Matlab-Simulink ${ }^{\circledR}$. Next, the methodologies are theoretically analyzed according to an ideal DC source and PEMFC source, and the PCS simulation model is carried out via the PSIM simulation program. Cosimulation between PEMFC and PCS is performed using the developed simulation model rather than the ideal DC source via the SimCoupler module provided by PSIM. The validity of the developed model is verified by the results from simulation.

\section{Fuel Cell Dynamics Model}

\subsection{Fuel Cell Modeling [10], [11]}

The chemical energy influencing the fuel cell output is explained by the Gibbs free energy. The theoretical maximum voltage is $1.229 \mathrm{~V}$ and determined by open circuit voltage $(\mathrm{OCV})$ if the reaction is reversible. 

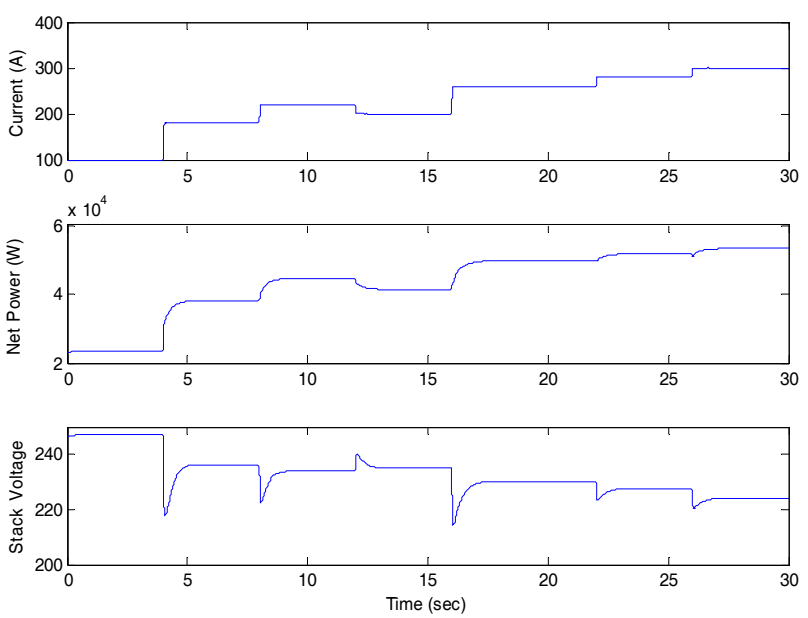

Fig. 1. Dynamic characteristics of the PEMFC system for a series of input step changes [10].

The theoretical fuel cell voltage at the irreversibility is determined by temperature and partial pressure of hydrogen, oxygen, and water; this can be calculated by the Nernst equation, as in (1):

$$
E=E^{0}+\frac{R T}{2 F} \ln \frac{P_{\mathrm{H}_{2}} P_{\mathrm{O}_{2}}^{1 / 2}}{P_{\mathrm{H}_{2} \mathrm{O}}}
$$

where $E^{0}$ is reversible cell voltage, $R$ is the gas constant $(8.3144 \mathrm{~J} / \mathrm{mol} K), T$ is temperature in Kelvin $(K), F$ is Faraday's constant $(96,485 \mathrm{C} / \mathrm{mol})$, and $P$ is the partial pressure of the corresponding gases.

The actual fuel cell voltage is always lower than the OCV due to irreversible voltage losses, corresponding to activation, ohmic, and concentration, as expressed by Eqs. (2) to (4). Therefore, about half of the OCV appears under the rated load condition.

$$
\begin{gathered}
\eta_{\text {act }}=\frac{R T}{\alpha n F} \ln \frac{i}{i_{o}} \\
\eta_{\text {ohmic }}=I R_{T} \\
\eta_{\text {conc }}=\frac{R T}{n F} \ln \left(1-\frac{i}{i_{L}}\right)
\end{gathered}
$$

where $\alpha$ is the transfer coefficient; $n$ is the number of electrons per reacting ion or molecule; $i_{o}$ is the exchange current density; $i$ is the current density; $R_{T}$ is for $r_{i}+r_{e}+r_{c} ; r_{i}$ is the ionic resistance; $r_{e}$ is the electronic resistance; $r_{c}$ is the contact resistance; and $i_{L}$ is the limit current density.

Exchange current density, one of the important factors in the efficiency of fuel cells, is proportional to the catalyst, catalyst area, electrode area, partial pressure of reactants, temperature, and activity energy. It can be derived as follows:

$$
I_{o}=I_{o}^{r e f} a_{c} L_{c}\left(\frac{P_{r}}{P_{r}^{r e f}}\right)^{\gamma} \exp \left[-\frac{E_{c}}{R T}\left(1-\frac{T}{T_{r e f}}\right)\right]
$$

where $I_{o}^{r e f}$ is the reference exchange current density at reference temperature and pressure based on actual catalyst surface area; $a_{c}$ is the catalyst specific area $\left(\mathrm{cm}^{2} / \mathrm{mg}\right) ; L_{c}$ is the catalyst loading $\left(\mathrm{mg} / \mathrm{cm}^{2}\right) ; \gamma$ is the reaction order with respect to the reactants; $P_{r}$ is the reactant partial pressure; $P_{r}^{r e f}$ is the reference pressure; $E_{c}$ is the activation energy, and $T_{r e f}$ is the reference temperature.

Consequently, the operating voltage of the PEMFC stack corresponds to OCV minus three polarizations. Additionally, the temperature, catalyst, and pressure according to mass flow exchange should be ensured when determining the output characteristic. Overall operating voltage of the PEMFC can be derived as

$$
V_{\text {cell }}=E-\left(i+i_{n}\right) r-A \ln \left(\frac{i+i_{n}}{I_{o}^{\text {ref }} a_{c} L_{c}\left(\frac{P_{r}}{P_{r}^{r f f}}\right)^{\gamma} \exp \left[-\frac{E_{c}}{R T}\left(1-\frac{T}{T_{r e f}}\right)\right]}\right)+B \ln \left(1-\frac{i+i_{n}}{i_{L}^{*} P}\right)
$$

where $i_{n}$ is the internal current; $P$ is the partial pressure, and the replacement notations are $A=\frac{R T}{\alpha n F}, B=\frac{R T}{n F}$.

A fuel cell manifests a dynamic "charge double layer" phenomenon. This characteristic can be represented by an electrical equivalent model, as shown in Fig. 2 [11]. This phenomenon details the incurring potential differences caused by accumulating hydrogen ions and electrons on both sides of the electrolyte while accumulating the minimum responsive gas density. The respective voltage loss and time constant due to the phenomenon can be derived as

$$
\begin{gathered}
d v_{c} / d t=\left(i / C_{c d y}\right)-\left(v_{c} / \tau\right) \\
\tau=C_{c d y} R_{a}=\left[C_{c d y}\left(V_{a c t}+V_{c o n}\right)\right] / i
\end{gathered}
$$

where $v_{c}$ is the voltage loss due to the charge double layer; $C_{c d y}$ is the equivalent capacitance; $\tau$ is the time constant; $R_{a}$ is the sum of the activation polarization resistance and the concentration polarization resistance; $V_{a c t}$ is the activation polarization; $V_{c o n}$ is the concentration polarization.

Consequently, the fuel cell stack voltage $\left(V_{\text {stack }}\right)$ can be expressed as

$$
V_{\text {stack }}=E-V_{\text {ohmic }}-v_{c}
$$

where $V_{\text {ohmic }}$ is the ohmic polarization.

The physical delay in the mechanical balance of plant (MBOP) system would cause a rapid drop in fuel cell output voltage. Increasing the load leads to higher current. In addition, the denser the gas, the higher the current becomes.

If the load is increased slowly or if the gas is supplied quickly to the fuel cell stack, the drop in voltage can be negated. However, in systems with large capacity and frequent load variations, physical friction resistance could lead to delays in gas flow, followed by a drop in output power. Consequently, the PEMFC undergoes sudden voltage drops, as well as nonlinear characteristics, due to 


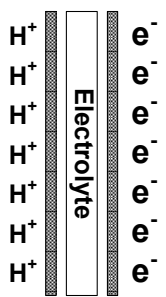

(a)

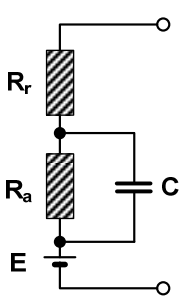

(b)
Fig. 2. Charge double layer in a fuel cell: (a) equivalent model at the surface of a fuel cell cathode; (b) electrical equivalent circuit of a unit cell.

electrochemical reaction. The magnitude of voltage drop fully depends on the type of fuel cells, physical condition of the balance of plant, MBOP geometric shape (function, length, and width of the gas supply system), fuel supply method, and amount of power variation. For these reasons, the voltage drops could not be standardized constantly due to the differences in the fuel cell design. For example, for the Ballard NEXA 1.2 kW PEMFC, about $15 \mathrm{~V}$ of fuel cell voltage is instantaneously decreased from 0 to $300 \mathrm{~W}$ load step change. Therefore, we adopted the RC first-order time delay function in order to realize a more flexible and dynamic characteristics:

$$
V_{\text {cell }}=A\left(1-e^{t / \tau}\right)
$$

\subsection{Fuel Cell Dynamic Simulation Model using Mat- lab-Simulink}

Based on the electrochemical equations above and the effect of MBOP, the PEMFC dynamic simulation model is realized using Matlab-Simulink, as shown in Fig. 3(a). based on the dynamic characteristics, the magnitude of the voltage drop and rising time fully depends on the physical conditions of BOP, MBOP geometric shape (e.g., function,

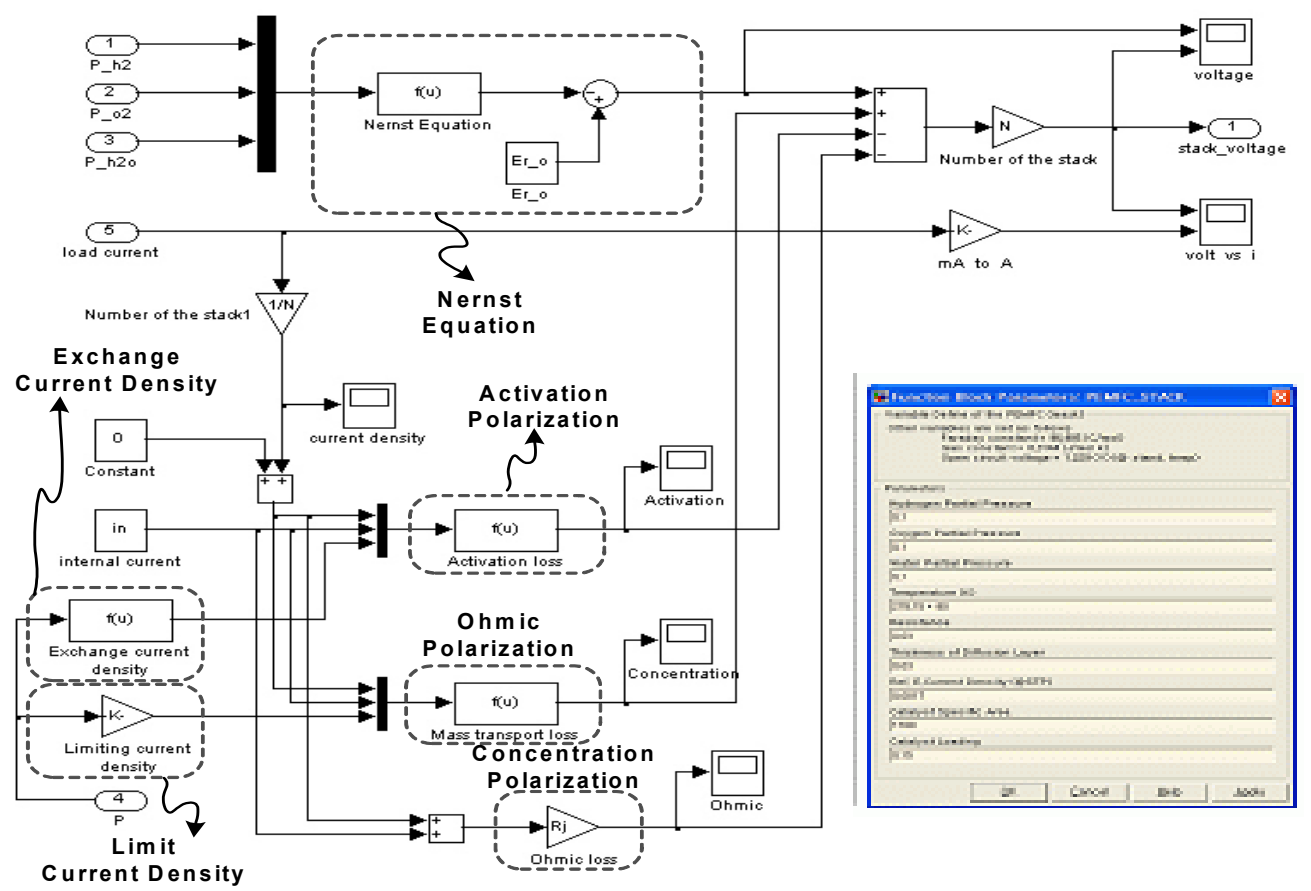

(a)

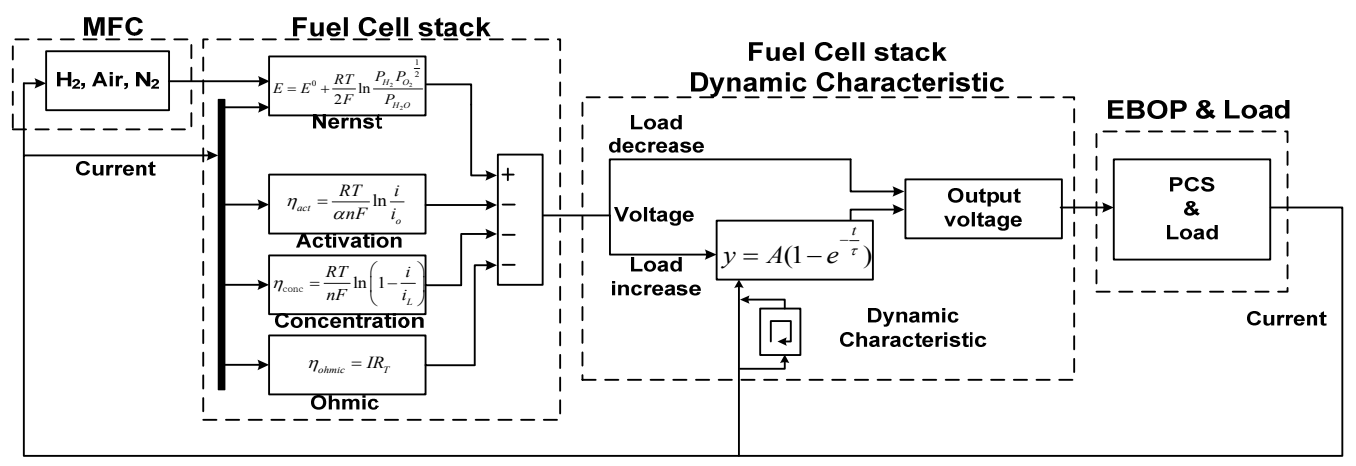

(b)

Fig. 3. Charge double layer of a fuel cell: (a) equivalent model at the surface of a fuel cell cathode; (b) electrical equivalent circuit of a unit cell. 
length, and width of the gas supply system), fuel supply method, and the amount of power variation. For these reasons, they could not be standardized constantly due to the differences in fuel cell design. Therefore, the proposed dynamic model should include changeable parameters for a specific fuel cell stack. Fig. 3(b) shows the block diagram of the developed dynamic model. The developed model provides that the voltage drop and recovery times, based on load variations, could be adjusted by the user. The detailed parameters for the developed simulation model are listed in Table 1.

Table 1. Simulation parameters for fuel cell model [11]

\begin{tabular}{c|c|c}
\hline Parameters & Symbols & Value [unit] \\
\hline Nernst voltage & $\mathrm{E}$ & $1.229[\mathrm{~V}]$ \\
\hline Internal current density & $\mathrm{i}_{\mathrm{n}}$ & $2\left[\mathrm{~mA} / \mathrm{cm}^{2}\right]$ \\
\hline Resistance & $\mathrm{r}$ & $0.1\left[\mathrm{ohm} / \mathrm{cm}^{2}\right]$ \\
\hline Gas constant & $\mathrm{R}$ & $8.3144[\mathrm{~J} / \mathrm{mol} \mathrm{K}]$ \\
\hline Temperature & $\mathrm{T}$ & $343.15[\mathrm{~K}]$ \\
\hline Faraday's constant & $\mathrm{F}$ & $96,485[\mathrm{C} / \mathrm{mol}]$ \\
\hline Exchange current density & $\mathrm{i}_{\mathrm{ec}}$ & $0.0017\left[\mathrm{~mA} / \mathrm{cm}^{2}\right]$ \\
\hline Number of cells & $\mathrm{N}$ & 48 \\
\hline Equivalent internal resistance & $\mathrm{R}_{\mathrm{a}}$ & $0.1\left[\mathrm{ohm} / \mathrm{cm}^{2}\right]$ \\
\hline Capacitance of charge double layer & $\mathrm{C}_{\mathrm{cdy}}$ & $0.6[\mathrm{~F}]$ \\
\hline
\end{tabular}

\subsection{Verification of Dynamic Fuel Cell Model}

To verify the developed dynamic simulation model, numerous simulations based on the performance indexes are performed. Fig. 4(a) shows the variations in cell voltage in terms of transfer coefficient. The transfer coefficient is inversely proportional to the activation polarization; therefore, the cell voltage is increased. The variations in activation polarization in relation to the exchange current densities are depicted in Fig. 4(b). Note that the higher the exchange current density, the higher the cell voltage increases.

As shown in Figs. 4(a) and 4(b), the transfer coefficient and exchange current density extensively affects activation polarization. Fig. 5(a) shows the effect of internal resistance; voltage drop increases as internal resistance is increased. The effect of the limit current density is presented in Fig. 5(b); the limit current density is inversely proportional to the output current of the PEMFC.

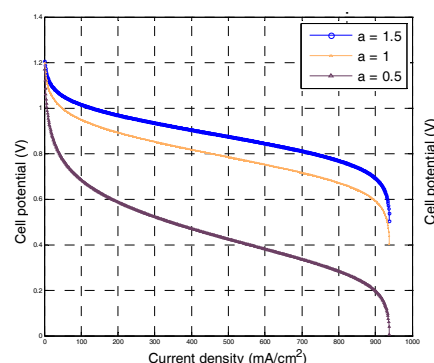

(a)

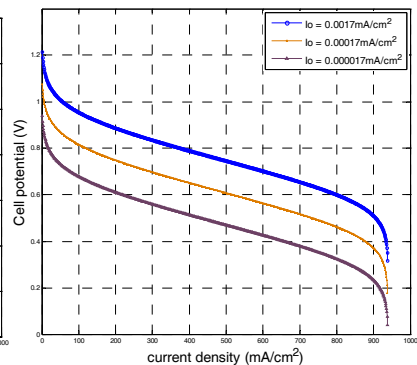

(b)
Fig. 4. Output voltage characteristics of PEMFC according to performance indexes: (a) effect of transfer coefficient; (b) effect of exchange current.

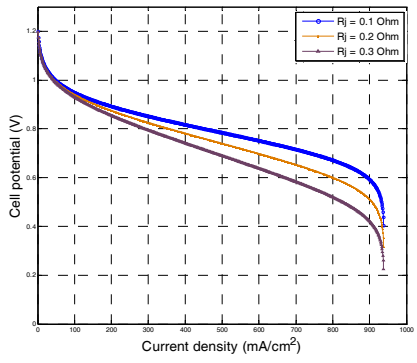

(a)

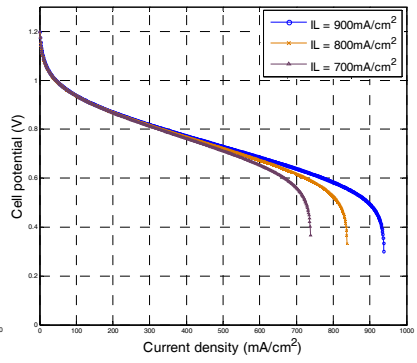

(b)
Fig. 5. Output voltage characteristics of PEMFC according to performance indexes: (a) effect of internal resistance; (b) effect of limit current density.

As implied by the simulation results, among the three polarizations, the activation polarization and ohmic polarization greatly affect cell voltage. The concentration polarization affects the maximum cell current.

Fig. 6 shows the power and cell voltage in relation to the partial pressures of oxygen, hydrogen, and water. The limit and exchange current density is proportional to the partial pressures. Hence, the output power of the PEMFC changes according to partial pressure. All simulation results agree with the theory presented in literature.

The simulation results of the dynamic characteristic of the PEMFC in terms of input step changes are depicted in Figs. 7(a)-(d). The left-side waveforms in Figs. 7(a), (b), and (c) are experimental results for the $1.2 \mathrm{~kW}$ Ballard NEXA PEMFC DC converter when load is varied from no load to $100 \mathrm{~W}, 200 \mathrm{~W}$, and $300 \mathrm{~W}$ conditions, respectively. The right-side waveforms in Figs. 7(a), (b), and (c) are the simulation results of the developed dynamic PEMFC model under identical conditions. The simulation results of the developed PEMFC model agree well with experimental results in terms of voltage drop and recovery time. Fig. 7(d) shows the entire dynamic process of the PEMFC for a

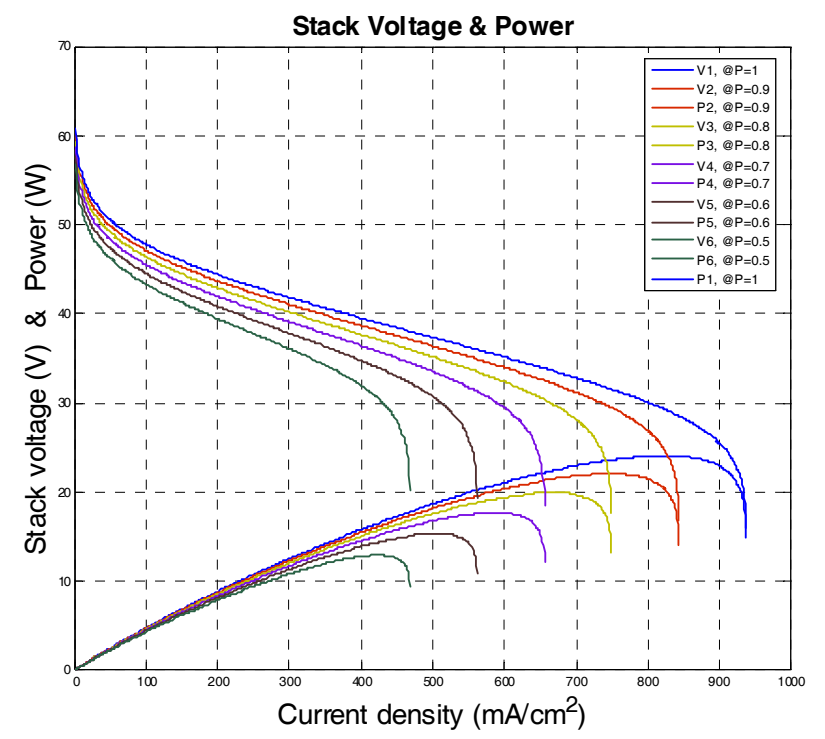

Fig. 6. Output voltage characteristics of PEMFC according to partial pressure. 

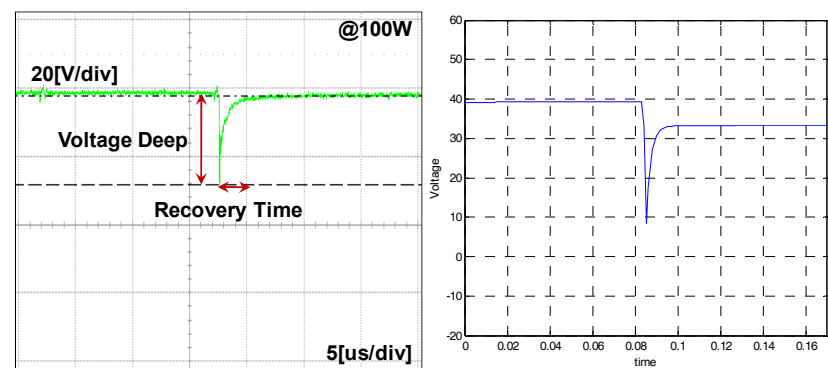

(a)
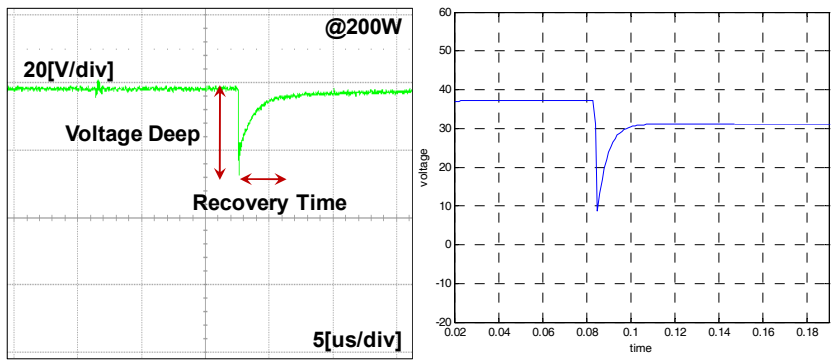

(b)
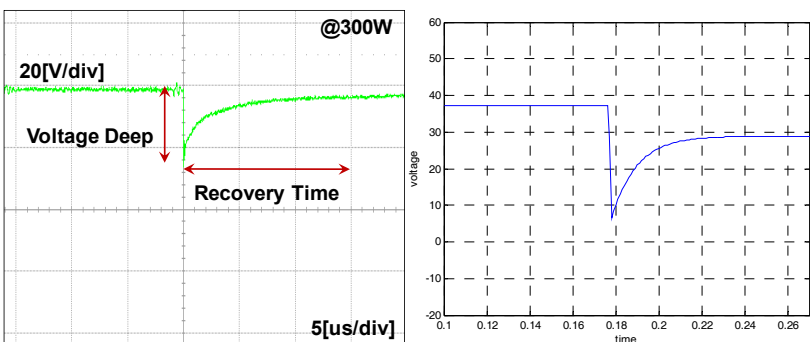

(c)

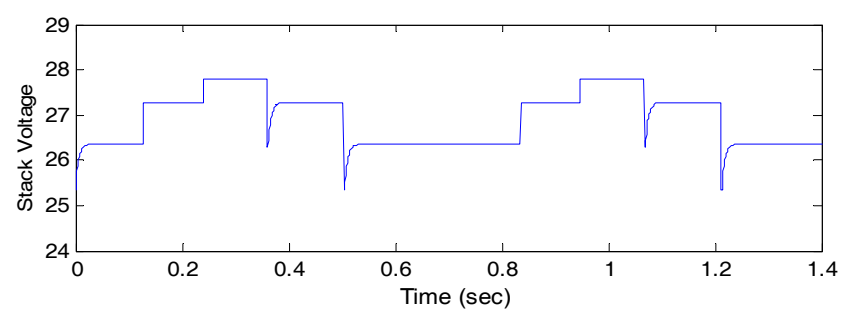

(d)

Fig. 7. Dynamic phenomena with experimental and simulation result with the developed model: Experimental and simulation results of PEMFC at (a) $100 \mathrm{~W}$, (b) 200W, and (c) 300W; (d) dynamic characteristic of PEMFC for a series of input step changes.

series of input step changes in time-domain using the developed PEMFC simulation model. These voltage drops and recovery times varies by fuel cell type, fuel supply, and MBOP characteristics. The developed model is designed to adjust voltage drops and recovery time by using controllable parameters.

\section{Design Considerations for Fuel Cell PCS}

For optimal FC-PCS design, voltage variation resulting from slow dynamics of the PEMFC should be considered because this variation has direct influence on the duty ratio of a DC-DC converter. In this section, comparative analysis is performed for the ideal DC source and the developed PEMFC source. For analysis of the FC-PCS, a boost DCDC converter is adopted.

\subsection{Comparative Analysis with Duty Ratio Variation}

Fig. 8(a) shows a step-up-type boost converter circuit, while Fig. 8(b) shows the inductor current with the ideal DC source. The duty ratio of a boost converter with the ideal DC source could be derived as the inductor's fluxlinkage balance at a steady state. This is expressed as

$$
D=\frac{V_{o}-V_{i}}{V_{o}}(0 \leq D \leq 1)
$$

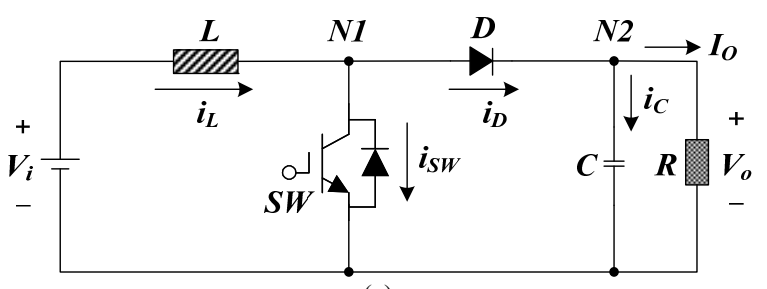

(a)

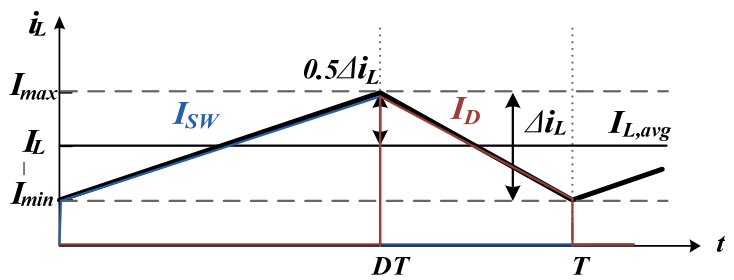

(b)

Fig. 8. (a) The boost DC-DC converter topology with ideal DC source. (b) Inductor current with the ideal DC source.

In contrast, when the PEMFC source is applied instead of the ideal DC source, the duty ratio of a boost converter is increased because of the dynamic characteristic of the PEMFC (i.e., sudden voltage drop and slow recovery). Therefore, the duty ratio of Eq. (11) is modified:

$$
D^{\prime}=1-\frac{V_{f c, r}-V_{d d}}{V_{o}}=D \cdot \frac{V_{o}-V_{f c, r}-V_{d d}}{V_{o}-V_{i}}
$$

where $V_{f c, r}$ is the PEMFC voltage at the rated power and $V_{d d}$ is the voltage drop due to fuel cell dynamics.

\subsection{Inductor Design}

By applying the PEMFC source to the boost converter, the rising slope of the inductor current is reduced as derived by (13), and falling slope is increased as derived by (14). Thus, the overall current fluctuations are reduced; that is, the inductance used in the boost converter for PEMFC 
matches that of the general boost converter. The detailed inductor current waveform is depicted in Fig. 9.

$$
\begin{gathered}
\frac{d i_{L_{R}}^{\prime}}{d t}=\frac{V_{f c, r}-V_{d d}}{L} \\
\frac{d i_{L_{F}}^{\prime}}{d t}=\frac{\left(V_{f c, r}-V_{d d}\right)-V_{o}}{L}
\end{gathered}
$$

\subsection{Design of Switch and Diode}

Fig. 10 represents the switch current with the PEMFC source. The switch current is identical to the recovery period of the inductor current, such that it can be derived as follows:

$$
I_{S W, \max }=\frac{I_{o, \max }}{D_{\min }^{\prime}}+\frac{\Delta i}{2}
$$

The switch current is additionally increased due to the dynamics of the PEMFC. The big current variations results in big temperature variations at the semiconductor junction, such that the lifetime of the switch is decreased because of thermal aging at the junction.

Therefore, a reasonable margin of current capacity for the switch is required for the precise calculation of power dissipation and thermal management.

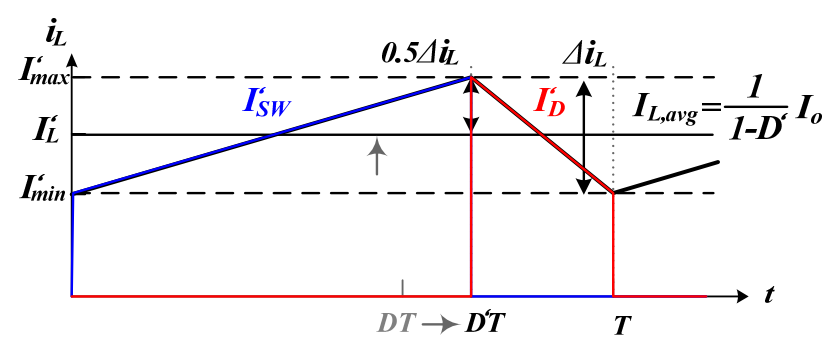

Fig. 9. Inductor current of the PEMFC source.

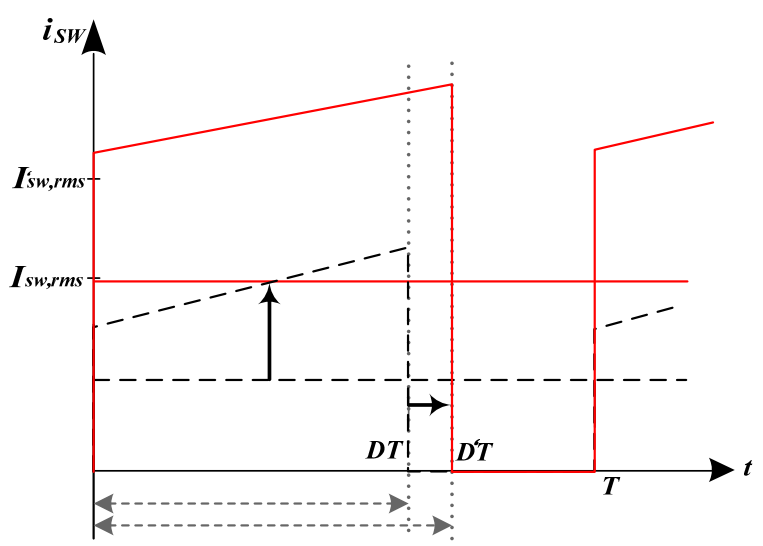

Fig. 10. Switch current of the PEMFC source.

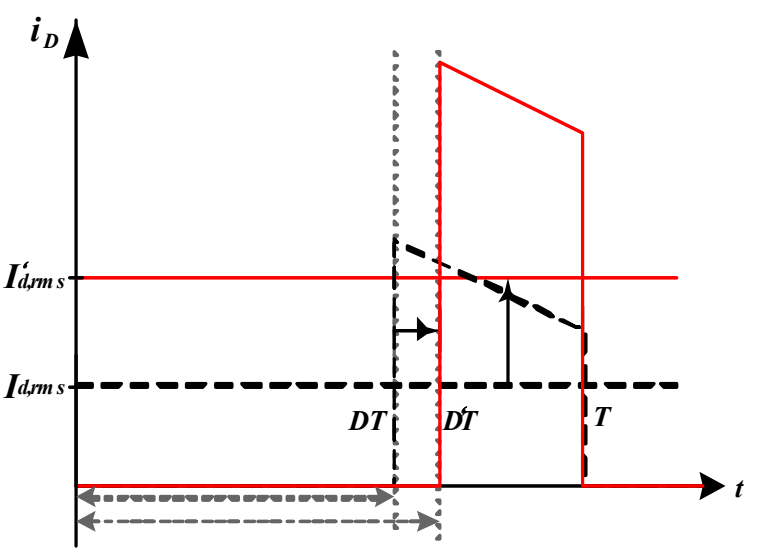

Fig. 11. Diode current of the PEMFC source.

The switch voltage across the drain and source for a metal-oxide-semiconductor field-effect transistor (MOSFET) is the sum of the output voltage of the boost converter and the voltage variation due to stray inductance $\left(L_{s}\right)$. It can be expressed as

$$
V_{D S}^{\prime}=V_{o}+L_{s} \frac{d i_{L s}^{\prime}}{d t}
$$

Assuming that the stray inductance in the circuit is identical to that of the FC-PCS, the voltage variation term $\left(L_{s}\left(d i_{L s} / d t\right)\right)$ increases because of a higher current variation $\left(d i_{L S} / d t\right)$ in relation to voltage drop. Accordingly, considering higher $d i_{L S} / d t$, the voltage margin of the switch should not exceed the reverse bias safety operation area (RBSOA).

The diode current is identical to the trough of the inductor current. Hence, it can be derived as

$$
I_{D, \max }=\frac{I_{o, \max }}{1-D_{\min }^{\prime}}+\frac{\Delta i}{2}
$$

Fig. 11 shows the diode current variation with PEMFC source. Similar to the switch design, the voltage and current rating of the diode are reflected based on reasonable margin.

\subsection{Capacitor Design}

The AC components of the diode current transform into the charging and discharging currents of the capacitor; that is, the capacitor ripple current is increased by the PEMFC, unlike in the ideal DC source to the boost converter. Equation (18) and Fig. 12 are the capacitor current equation and waveform, respectively.

$$
i_{c, r m s}^{\prime}=I_{o, \max } \sqrt{\frac{V_{o}-\left(V_{f c, r}-V_{d d}\right)}{V_{f c, r}-V_{d d}}}
$$




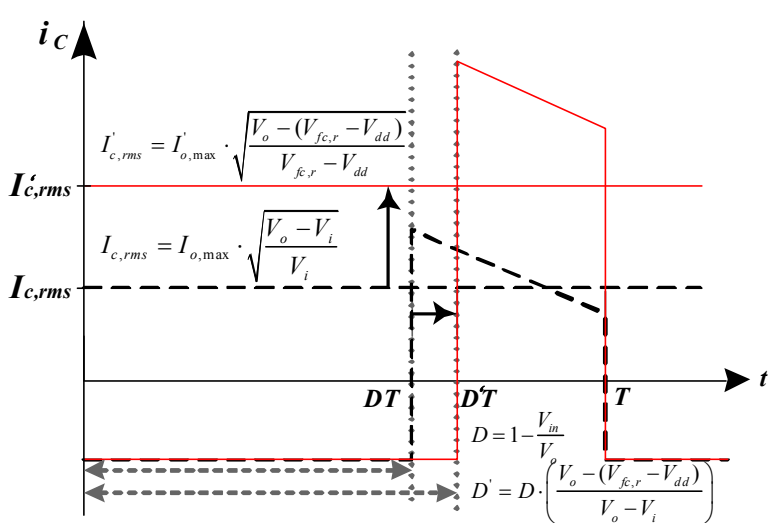

Fig. 12. Capacitor current of the PEMFC source.

\section{Simulation Verification}

\subsection{Advanced Interchangeable Dynamic Simulation Model}

To verify the validity of the developed dynamic simulation model and the theoretical analysis of the optimal design methodology for the FC-PCS, computer simulation is performed using the developed PEMFC model in Section II. For the PCS topology, a voltage-fed full-bridge DC-DC converter and a single-phase unipolar sinusoidal pulse width modulation DC-AC inverter with $1 \mathrm{~kW}$ are adopted. The power electronics topology and control algorithm are determined by using the PSIM simulation program. The interchangeable simulation by using Matlab-Simulink and PSIM is then performed in order to analyze the exact phenomena with the help of SimCoupler module in PSIM. The simulation parameters are detailed in Table 2. Fig. 13 shows the block diagram of the PCS topology and the control algorithm.

Fig. 14 shows the block diagram of the advanced interchangeable dynamic simulation model. The PEMFC dynamic simulation model using Matlab-Simulink and the

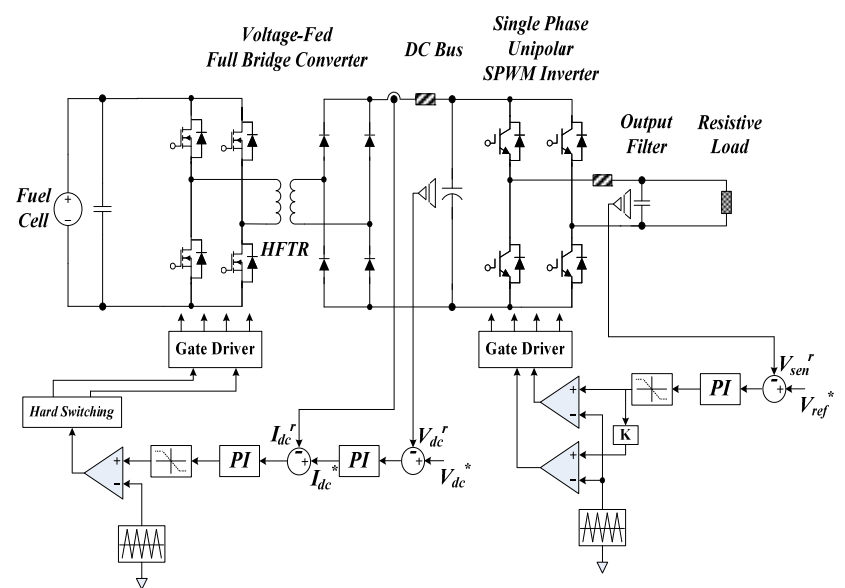

Fig. 13. Block diagram for PCS topology and control algorithm.
Table 2. PCS Simulation Parameters

\begin{tabular}{c|c|c|c}
\hline Parameters & $\begin{array}{c}\text { Value } \\
\text { for converter }\end{array}$ & $\begin{array}{c}\text { Value } \\
\text { for inverter }\end{array}$ & Unit \\
\hline Rated power & 1200 & 1200 & $\mathrm{~W}$ \\
\hline Input voltage & $26-42$ & 380 & $\mathrm{~V}_{\mathrm{dc}}$ \\
\hline Output voltage & 380 & 220 & $\mathrm{~V}_{\mathrm{dc}} / \mathrm{V}_{\mathrm{ac}}$ \\
\hline Output current & 3.16 & 5.45 & $\mathrm{~A}_{\mathrm{dc}} / \mathrm{A}_{\mathrm{ac}}$ \\
\hline High frequency TR & $3: 36$ & - & turn ratio \\
\hline DC link capacitor & 1500 & 1500 & $\mathrm{uF}$ \\
\hline LC filter & $3 /-$ & $3 / 20$ & $\mathrm{mH} / \mathrm{uF}$ \\
\hline Switching frequency & 60 & 10 & $\mathrm{kHz}$ \\
\hline
\end{tabular}

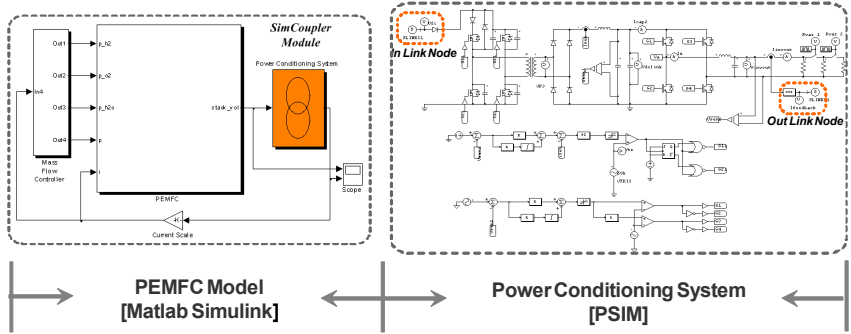

Fig. 14. Block diagram of advanced interchangeable dynamic simulation model.

PCS using PSIM are interconnected through the "SLINK_IN" and "SLINK_OUT" elements in the PSIM. The output voltage of the PEMFC from the Matlab-Simulink is connected to the input of the PCS in the PSIM, and the output current of the PCS returns to the PEMFC model using a scaled current density $\left(\mathrm{A} / \mathrm{cm}^{2}\right)$. To execute interchangeable simulation, the "cct" file for the netlist of the PSIM is generated by operating the "Generate Netlist File." The generated cct file is linked to the Matlab-Simulink through a Sim Coupler module, and the "Time step" and "Total time" in Matlab-Simulink and PSIM is synchronized with each other. A "solver" of the Matlab-Simulink, "ode5 (Dormand-Prince)," is selected [12],[13].

\subsection{Simulation Results}

The converter output voltage, inverter output voltage, and inverter current when the existing ideal DC source is applied are shown in Fig. 15(a). The input voltage is constant even though the output power is suddenly changed; however, it could not reflect the actual phenomena. For the PEMFC source, Fig. 15(b) presents the input voltage exchange, up to maximum of $6.8 \mathrm{~V}$, according to the load step change under identical conditions. It can be regulated by tuning the range of voltage exchange.

Figs. 16(a) and 16(b) represent the exchange of switching duty ratio of the DC-DC converter. As mentioned in the theoretical analysis, a sufficient consideration of the current stress caused by duty increase is required during FCPCS design.

Figs. 17(a) and 17(b) represent the variations in duty ratio due to the dynamic characteristic of the PEMFC. Fig. 17 (a) shows the voltage dynamics of the PEMFC with a $20 \mathrm{~V}$ 


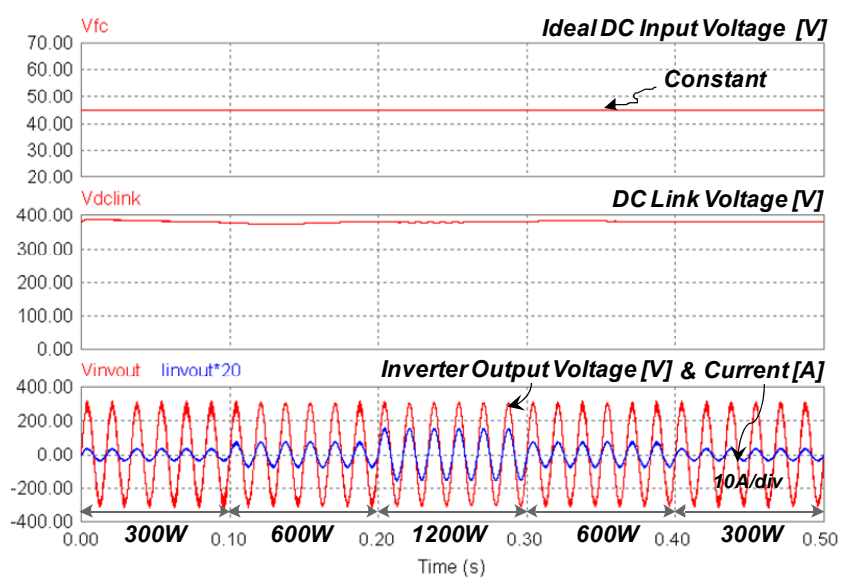

(a)

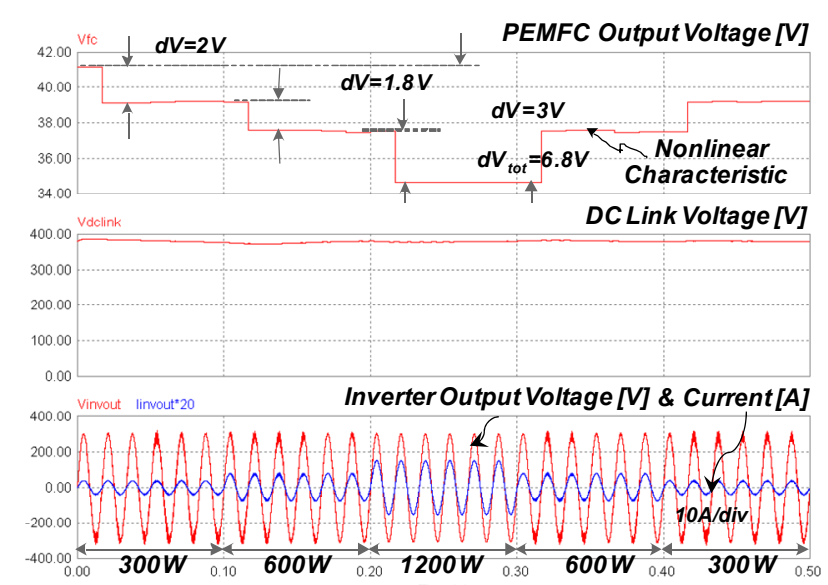

(b)

Fig. 15. Simulation waveforms according to load variation. (a) using ideal DC source and (b) using developed PEMFC source.

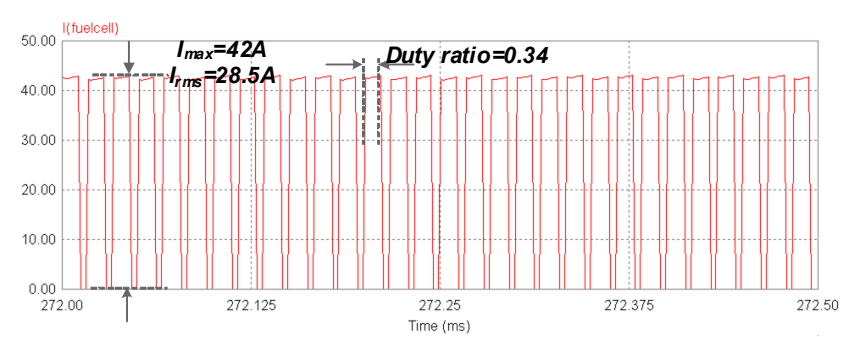

(a)

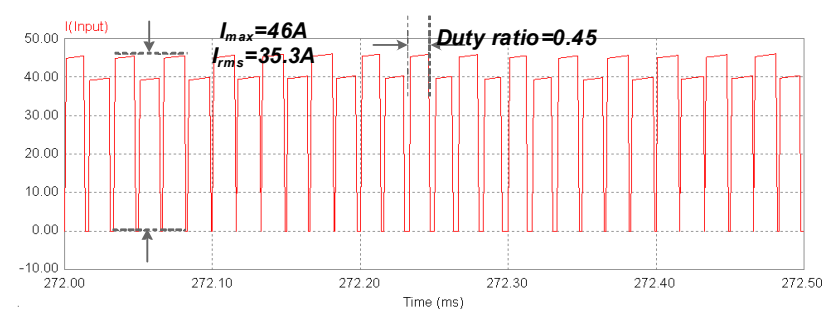

(b)

Fig. 16. Duty ratio according to load variation (a) using ideal DC source and (b) using proposed PEMFC source.

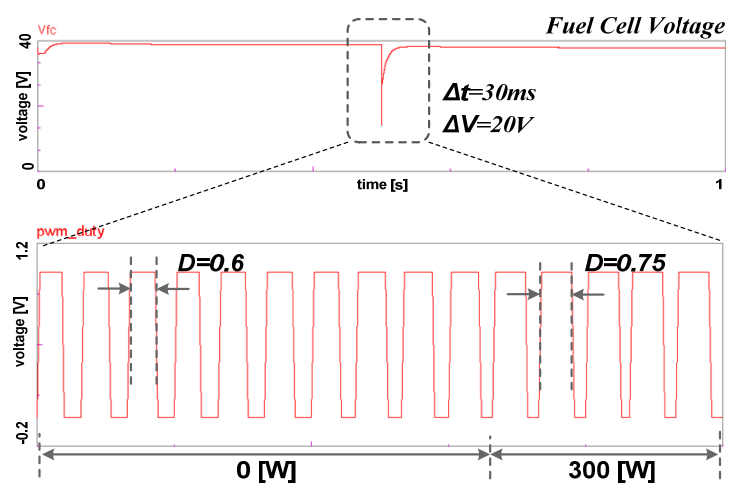

(a)

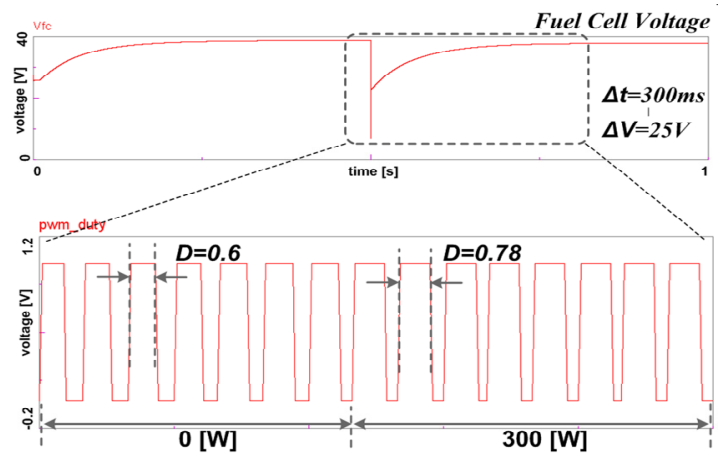

(b)

Fig. 17. Duty ratio variation (a) under $20 \mathrm{~V}$ of voltage deep and $30 \mathrm{~ms}$ of recovery time, and (b) under $25 \mathrm{~V}$ of voltage deep and $300 \mathrm{~ms}$ of recovery time.

voltage drop and $30 \mathrm{~ms}$ recovery time at the load step change from 0 to $300 \mathrm{~W}$. As a result, duty ratio varies from 0.6 to 0.75 . However, this does not seriously affect the duty ratio because of fast recovery time. On the other hand, Fig. 17 (b) represents the voltage dynamics at $25 \mathrm{~V}$ voltage drop and $300 \mathrm{~ms}$ recovery time under identical conditions, as in Fig. 17(a). Before PEMFC voltage recovers to a steady state, the duty ratio varies from 0.6 to 0.78 , mainly due to bigger voltage drop and longer recovery time. Hence, relatively higher stress is applied to the passive and active devices in the FC-PCS.

Fig. 18 shows the practical PCS simulation schematic, including stray inductance in the circuit, and the parasitic capacitance of the MOSFET. Figs. 19(a) and 19(b) illustrate the voltage overshoot of the MOSFET when applied with the ideal DC source and the PEMFC model, respectively. When the PEMFC is applied to the PCS, the voltage stress increases by about $120 \%$ compared with those applying the ideal DC source; this is due to the higher $d i_{L s} / d t$.

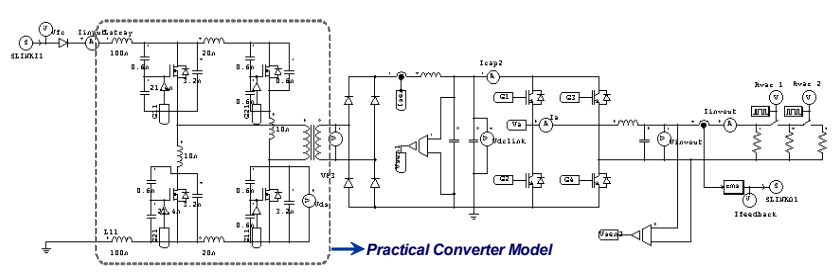

Fig. 18. Practical PCS simulation model. 


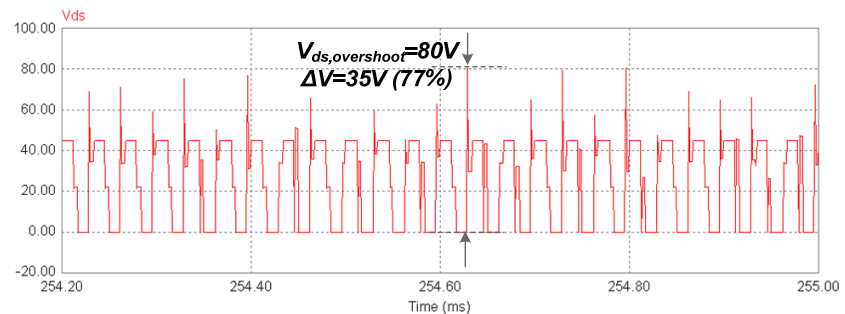

(a)

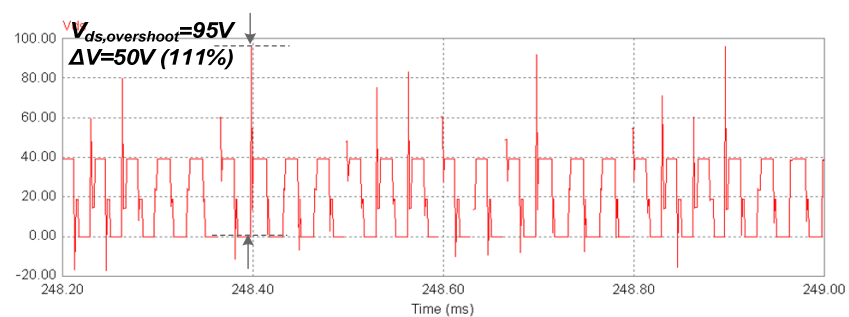

(b)

Fig. 19. Switch voltage waveform at transient conditions (a) under the ideal DC source and (b) under the proposed PEMFC source.

\section{Conclusion}

In this paper, for the optimal design of the FC-PCS, dynamic characteristic modeling and a software simulation of the PEMFC are implemented using Matlab-Simulink. The PCS simulation model is also conducted using PSIM, which offers advantage when used for circuit analysis. An advanced interchangeable simulation model is then performed using a SimCoupler module in PSIM to analyze the exact mechanism in the FC-PCS resulting from the PEMFC dynamics. Comparative analysis is performed for the ideal DC source and the modeled PEMFC source. Through the developed co-simulator, it is expected that it could be fully utilized for optimal design of FC-PCS, such as in thermal age forecasting of the switch and the diode, analysis of transient conditions, forecasting of capacitor lifespan, optimal design of controller and compensator, among many others.

\section{References}

[1] Y. Sampath, A. Davari, A. Feliachi and T. Biswas, "Modeling and simulation of the dynamic behavior of a polymer electrolyte membrane fuel cell," J. of Power Sources, Vol. 124, pp. 104-113, 2003.

[2] G. Y. Choe, J. S. Kim, H. S. Kang, B. K. Lee and W. Y. Lee, "Proton Exchange membrane fuel cell (PEMFC) modeling for high efficiency fuel cell balance of plant (BOP)," IEEE ICEMS 2007, pp. 271-276, 2007.

[3] J. S. Kim, G. Y. Choe, B. K. Lee, D. S. Oh, J. W. Kim and J. S. Shim, "Optimal Design Methodology for FC-PCS using Fuel Cell Simulator," IEEE INTELEC 2009, pp. 1-6, 2009.
[4] W. J. Choi, J. W. Howze, P. Enjeti, "Development of an equivalent circuit model of a fuel cell to evaluate the effects of inverter ripple current," $J$. of power sources, 158, pp. 1324-1332, 2006

[5] M. J. Khan, M. T. Iqbal, "Modeling and analysis of electro-chemical, thermal, and reactant flow dynamics for a PEM fuel cell system," Fuel cells 05, Vol. 5, Issue 4, pp. 463-475, 2005

[6] D. Yu, S. Yuvarajan, "A novel circuit model for PEM feul cells," IEEE APEC2004, Vol. 1, pp. 362-366, 2004.

[7] D. Natarajan, T. V. Nguyen, "Three-dimensional effects of liquid water flooding in the cathode of a PEM fuel cell," J. of Power Sources, Vol. 115, pp. 66-80, 2003.

[8] L. Y. Chiu, B. Diong, R. S. Gemmen, “An Improved Small-Signal Model of the Dynamic Behavior of PEM Fuel Cell," IEEE Trans. Ind. Appl., Vol. 40, Issue 4, pp 970-977, July-Aug. 2004.

[9] J. M. Correa, F. A. Farret, L. N. Canha, M. G. Simoes, "An Electrochemical-based fuel-cell model suitable for electrical engineering automation approach," IEEE Trans. Ind. Electron., Vol. 51, No.5, pp. 11031111, 2004.

[10] J. T. Pukrushpan, A. G. Stefanopoulou, H. Peng, "Control of Fuel cell Power Systems," Springer.

[11] J. Larminie and A. Dicks, Fuel Cell Systems Explained, 2nd ed., Wiley, 2003, pp. 17-59.

[12] MATLAB, Simulink ${ }^{\circledR}$ User manual.

[13] PSIM User's Guide, Version 6, 2003.

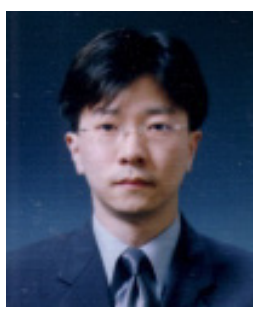

Jong-Soo Kim received his M.S. degree in Electrical Engineering from Sungkyunkwan University, Suwon, Korea, in 2008. Since 2008, he has worked for his Ph.D. in Electrical Engineering at Sungkyunkwan University. His research interests include ecofriendly vehicle technologies, power conditioning systems for renewable energy, and PM motor drives.

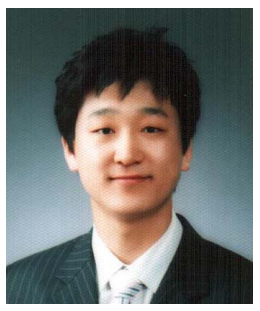

Gyu-Yeong Choe received his M.S. degree in electrical engineering from Sungkyunkwan University, Suwon, Korea, in 2008. Since 2008, he has worked for his Ph.D. in Electrical Engineering at Sungkyunkwan University. His research interests include renewable energy source modeling, renewable energy hybrid systems, battery chargers for PHEV/EV, and interleaved DC-DC converters. 


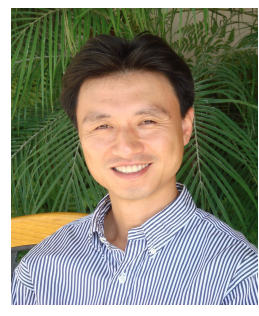

Byoung-Kuk Lee received his B.S. and M.S. degrees in Electrical Engineering from Hanyang University, Seoul, Korea, in 1994 and 1996, respectively, and his Ph.D. from Texas A\&M University, College Station, TX, USA in 2001.

In 2003 to 2005, he has been a Senior Researcher at the Power Electronics Group, KERI, Changwon, Korea. In 2006, he joined the School of Information and Communication Engineering, Sungkyunkwan University, Suwon, Korea, as an Assistant Professor. His research interests include electric vehicles, sensorless drives for high-speed PM motors, power conditioning systems for renewable energy, modeling and simulation, and power electronics.

Prof. Lee is a recipient of the Outstanding Scientists of the $21^{\text {st }}$ Century from IBC and is listed in the $200862^{\text {nd }}$ edition of "Who's Who in America" and in the $200926^{\text {th }}$ edition of "Who's Who in the World." Prof. Lee is an Associate Editor in the IEEE Transactions on Industrial Electronics and an IEEE Senior Member.

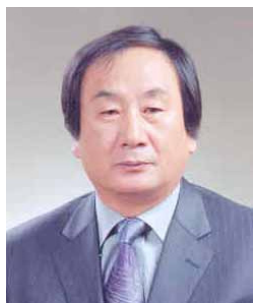

Jae-Sun Shim received his B.S. and $\mathrm{Ph} . \mathrm{D}$. degree in Electrical Engineering from Sungkyunkwan University, Suwon, Korea, in 1973 and 1989, respectively, and his M.S. in Electrical Engineering from Dankook University, Seoul, Korea, in 1979.

$\mathrm{He}$ has been with Kangwon National University at Samcheok, Samcheok, Korea, as professor in the Department of Electrical Engineering since 1975. 